\title{
Transport disadvantage, social exclusion, and subjective well- being: The role of the neighborhood environment-evidence from Sydney, Australia
}

\author{
Liang Ma (Corresponding author) \\ RMIT University \\ liang.ma@rmit.edu.au
}

\author{
Jennifer L. Kent \\ The University of Sydney \\ Jennifer.kent@sydney.edu.au
}

\section{Corinne Mulley}

The University of Sydney

Corinne.mulley@sydney.edu.au

\begin{abstract}
This study explores the effects of the neighborhood environment on transport disadvantage, social exclusion, personal health and subjective well-being (SWB) using survey data collected in Sydney, Australia. The data is analyzed using structural equation modelling (SEM). Overall, our model supports the hypothesis that a walkable neighborhood environment helps to reduce transport disadvantage and increase social inclusion. Neighborhood density has negative effects on both physical and mental health, but a positive effect on SWB. Further, a cohesive neighborhood environment is associated with less transport disadvantage, more engagement in political and civic activities, more social help, better mental health and higher SWB. By contrast, perception of crime in a neighborhood is associated with more transport disadvantage and worse physical health. Neighborhood aesthetics and the neighborhood social environment have stronger effects on SWB than other neighborhood environment characteristics.
\end{abstract}

Keywords: Transport disadvantage, social exclusion, subjective wellbeing, built environment

\section{Article history:}

Received: October 31, 2016

Received in revised form:

May 11, 2017

Accepted: November 29, 2017

Available online: January 5,

2018

\section{Introduction}

The links between transport disadvantage, social exclusion and poor health and well-being outcomes are well established (Church, Frost, \& Sullivan, 2000; Currie et al., 2009; Currie \& Stanley, 2007; Delbosc \& Currie, 2011a; Lucas, 2012; Stanley, Hensher, Stanley, \& Vella-Brodrick, 2011). Good transport facilitates access, which enables participation in the activities that are important in life (Lucas, 2012). These activities include gainful employment, education and social and familial interactions (Ettema, Gärling, Olsson, \& Friman, 2010), as well as practices of self-care such as routine physical activity and healthy eating (Thompson \& Kent, 2014).

Copyright 2018 Liang Ma, Jennifer L. Kent \& Corinne Mulley

http://dx.doi.org/10.5198/jtlu.2018.1008

ISSN: 1938-7849 | Licensed under the Creative Commons Attribution - Noncommercial License 3.0

The Journal of Transport and Land Use is the official journal of the World Society for Transport and Land Use (WSTLUR) and is published and sponsored by the University of Minnesota Center for Transportation Studies. This paper is also published with additional sponsorship from WSTLUR. 
While transport disadvantage features regularly in research, it remains a concept that is notoriously difficult to define and measure. These difficulties emanate from the fact poor access results from complex interactions of built, cultural, locational, socio-economic and demographic variables. This complexity is evident in many cities around the world, including those in Australia, which have "grown up" post the industrial revolution, and in the era of private car emergence. This history has ensured a structure that has potential to both augment and complicate experiences of transport disadvantage. For example, the housing price gradient in these cities generally follows that of residential density, sloping from high to low as distance from the core to periphery increases. Low income populations are therefore often left with little choice but to live in outer suburban areas. The concentration of employment, service and recreational opportunities at the core subsequently forces these populations to travel long distances, and the lack of public transport options ensures that covering these distances is both difficult and expensive. Furthermore, distance, and a paucity of infrastructural provision, limits walking and cycling for transport, as well as other alternatives to private car ownership such as car sharing (Daniels \& Mulley, 2012). In short, these lower income households are forced into the expense of private car ownership, requiring an allocation of relatively more income to cover the costs of transport necessary for social inclusion, and the maintenance of a reasonable standard of individual well-being.

Previous studies linking transport disadvantage with social exclusion and poor well-being have explored the complexity described above, focusing primarily on the role of accessibility to different transport modes. Private car ownership and access to reliable public transport are often suggested as precursors to viable employment and participation in other activities and interactions, with this relationship particularly clear in research from low density Australian and North American contexts. For example, using data on welfare recipients in Alameda County, California, Cervero, Sandoval, and Landis (2002) found that car ownership was a significant predictor of transition to employment, while public-transport service quality variables were largely insignificant. Grengs (2010) also found that policies to facilitate private car use were most effective in improving employment opportunities for lower income residents in Detroit. Ong and Miller (2005) compared the impacts of spatial mismatch (the geographic separation of workers and jobs) and lack of access to a private automobile on neighborhood unemployment rates in metropolitan Los Angeles. They found that the lack of access to a private vehicle was relatively more important as a determinant of poor labor-market outcomes, particularly in low income neighborhoods. Similar findings have been reported in Australia. Currie et al. (2009) assessed transport disadvantage and social exclusion on the urban fringe in Melbourne, Australia. They identified two types of transport disadvantaged groups - those who are forced to own a car and those without a car. They found that households forced to own cars are primarily those on low incomes. These households were found to be highly car dependent, lack alternative transport options, face high transport costs relative to income, and make less trips than the average car owning household in the same city.

Despite the focus on links between city structure and transport disadvantage evident in the studies reviewed above, little research has systematically investigated the role of more micro-characteristics of the neighborhood environment in shaping elements of transport disadvantage, social exclusion and well-being. We conceptualize the neighborhood environment as made up of variables such as street design, connectivity, density and diversity of destinations, as well as elements of the social environment autogenous to the neighborhood, defined by neighboring practices, shared values and trust. Studies that have incorporated considerations of these environmental characteristics, generally concentrate on interactions at the aggregate geographic scale (for example, Delbosc \& Currie, 2011c, and Hurni, 2007). We propose that to really understand potential links between the neighborhood environment, transport disadvantage and well-being, research must be undertaken from the bottom up, starting with individual responses. This study fills this research gap.

We explore the potential effects of the built environment on transport disadvantage, social exclu- 
sion and well-being, at the individual level. The purpose is to identify environmental indicators that can inform policies addressing transport disadvantage and social exclusion in metropolitan Sydney. This research also aims to contribute to existing theories of links between transport disadvantage, social exclusion, well-being and health, through a more robust consideration of the impact of the neighborhood environment on these links.

The neighborhood environment potentially influences transport disadvantage, social exclusion and well-being both directly and indirectly. First, travel characteristics, such as travel mode choice and travel cost, are endogenous to the neighborhood built environment (Boarnet \& Sarmiento, 1998). Research consistently demonstrates a link between transport practices and neighborhood built environment characteristics, including residential density, land-use diversity, and pedestrian-friendly design (Ewing \& Cervero, 2010). Increased diversity, for example, provides opportunities for the divestment of service and employment uses away from the city core, with subsequent impacts on distance, travel time and the viability of modes such transit, walking and cycling in suburban areas. This provides the residential populations of these areas, including lower income groups, with the opportunity to avoid the expense of private car ownership, and potentially moderates exposure to transport disadvantage. Second, the neighborhood environment can also more immediately influence health and well-being, quite outside of its influence on transport and access opportunities. Numerous studies have concluded that people living in walkable, mixed-use neighborhoods have higher well-being through greater connection to community, better access to healthy food, and opportunities for recreational and incidental physical activity, as compared to those living in homogenous areas designed to be navigated by car rather than on foot (Frank \& Engelke, 2001; Kent \& Thompson, 2014). There is also nascent research suggesting that the built environment impacts elements of subjective well-being, quite outside of its influence on health (see, for example, Pfeiffer \& Cloutier, 2016). Subjective well-being is a broad concept, however its defining feature is self-evaluation. In colloquial terms it can simply be considered self-appraisal of whether one is happy, or not (Diener, 2000).

To inform our theoretical and empirical explorations, we have developed a framework to link the neighborhood environment, travel characteristics, social exclusion and subjective well-being. This framework is illustrated in Figure 1.

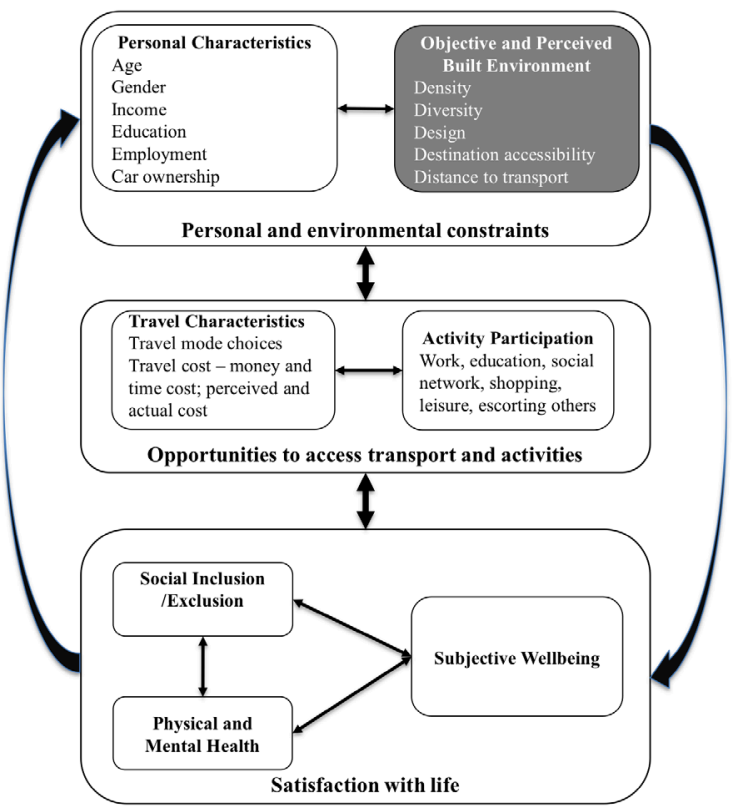

Figure 1: Links between the neighborhood environment, transportation, and subjective well-being 


\section{Method}

\subsection{Data and variables}

Our primary method of data collection was a self-administered 13-page survey, distributed in two stages. In the first stage, we mailed out the surveys to households in four neighborhoods in Sydney, Australia in April 2016. The four neighborhoods were purposefully selected. We first created a list of all neighborhoods in the Sydney Greater Metropolitan Area with a Socio-Economic Indexes for Areas (SEIFA) score within the lowest $20 \%$ of the state. SEIFA is an index developed by Australian Bureau of Statistics to rank areas in Australia according to relative socio-economic advantage and disadvantage. Each neighborhood was then categorized as having one of the following typologies: car-dependent, good access to public transport but not walkable, walkable but poor access to public transport, and walkable with good access to public transport. This categorization was informed by measures of street layout, accessibility to business establishments and accessibility to public transport. We used Google maps, "Walk score" and the PTAL score (public transport accessibility level score) (Transport for London, 2010) for this categorization. 1,600 household addresses, including resident names, were purchased from a list company, 400 for each neighborhood. We had hoped that a personally addressed survey would result in a more favorable response rate. A survey package consisting of the survey, a participant information statement, and a reply paid envelope was delivered by post to each of the addresses. The survey also contained details of an online option for survey completion. Each household returning a completed survey was offered the option to enter a draw to win one of ten $\$ 50$ gift cards. The survey was mailed on March 31st, 2016 and would have arrived at the target households by April 4 2016, giving two weeks before the required return date. A reminder letter was sent to all addresses after a week, again in an effort to increase the response rate. The survey itself, and the process of participant recruitment, was granted approval by the ethics committee of the authors' institution. The number of responses from stage one totaled 117. This is equivalent to an $8 \%$ response rate based on valid names and addresses only (117 out of 1,600 addresses were returned as not valid). Considering the length of the survey (20-25 minutes), and special characteristics of the target neighborhoods (socially disadvantaged neighborhoods), this response rate is respectable. However, the sample size was relatively small to estimate the final models. Further, the sample was clearly not representative. The respondents were more likely to be male ( $75 \%$ versus $51 \%$ for the Sydney metropolitan area) and older (median age of 62 versus median age of 36 for the Sydney metropolitan area) (Australian Bureau of Statistics, 2011).

A second round of data collection was, therefore, conducted to enlarge our sample for the analysis. In the second stage, we worked with a panel company to collect the data through an online survey. Quotas were used based on gender, age, and income to obtain a sample that could represent the population. The survey was conducted between August 22 and 30. The panel company provides a direct money incentive for the participants. For quality assurance purpose, two "trap" questions ${ }^{1}$ were added into the survey following Downes-Le Guin, Baker, Mechling, and Ruylea (2012). Those who failed to correctly answer both questions were screened out. Further, a minimum time requirement for filling out the survey was also embedded in the survey to identify the "speedster" who speed through questionnaires without reading questions and/or possible answers. The number of responses from second stage totaled 445 .

The data collected from stage one and stage two were combined for the following data analysis. The total sample size is 562 . Table 1 provides the sample characteristics. Although the quotas set up in the survey helped to achieve a sample that is close the population in terms of age, gender, and household income, the sample is still not perfectly representative of the population, with relatively lower employment rate (58\% versus $88 \%$ for the Sydney metropolitan area) when compared with census data.

\footnotetext{
${ }^{1}$ The two questions are: (1) “This question is for quality assurances purposes for our survey. Please select “'Strongly disagree' below”; (2) "This question is for quality assurances purposes for our survey. Please select 'Strongly agree' below”.
} 
Table 1: Characteristics of respondents

\begin{tabular}{|c|c|c|}
\hline Age & Number & Percent \\
\hline $18-34$ & 146 & 26.3 \\
\hline $35-44$ & 113 & 20.3 \\
\hline $45-64$ & 199 & 35.8 \\
\hline 65 and above & 98 & 17.6 \\
\hline \multicolumn{3}{|l|}{ Gender } \\
\hline Male & 307 & 55.2 \\
\hline Female & 249 & 44.8 \\
\hline \multicolumn{3}{|l|}{ Marital status } \\
\hline Single, never married & 155 & 27.7 \\
\hline Married & 281 & 50.3 \\
\hline Living with partner & 51 & 9.1 \\
\hline Separated/Divorced/Widowed & 72 & 12.9 \\
\hline \multicolumn{3}{|l|}{ Employment } \\
\hline Not employed & 79 & 14.2 \\
\hline Employed full time & 232 & 41.6 \\
\hline Employed part time & 91 & 16.3 \\
\hline Retired & 113 & 20.3 \\
\hline Disabled, unable to work & 20 & 3.6 \\
\hline Other & 23 & 4.1 \\
\hline \multicolumn{3}{|l|}{ Annual housebold income (before tax) } \\
\hline Negative or Zero Income & 7 & 1.3 \\
\hline$\$ 1-\$ 9,999$ per year & 9 & 1.7 \\
\hline$\$ 10,000$ - $\$ 19,999$ per year & 19 & 3.5 \\
\hline$\$ 20,000$ - $\$ 29,999$ per year & 47 & 8.7 \\
\hline$\$ 30,000$ - $\$ 39,999$ per year & 42 & 7.8 \\
\hline$\$ 40,000$ - $\$ 49,999$ per year & 51 & 9.5 \\
\hline$\$ 50,000$ - $\$ 59,999$ per year & 45 & 8.4 \\
\hline$\$ 60,000$ - $\$ 79,999$ per year & 70 & 13.0 \\
\hline$\$ 80,000$ - $\$ 99,999$ per year & 75 & 13.9 \\
\hline$\$ 100,000$ - $\$ 124,999$ per year & 64 & 11.9 \\
\hline$\$ 125,000$ - $\$ 149,999$ per year & 42 & 7.8 \\
\hline$\$ 150,000$ - $\$ 199,999$ per year & 42 & 7.8 \\
\hline$\$ 200,000$ or more per year & 25 & 4.7 \\
\hline \multicolumn{3}{|l|}{ Property ownership } \\
\hline Rent & 167 & 29.9 \\
\hline Own & 368 & 65.8 \\
\hline Other & 24 & 4.3 \\
\hline \multicolumn{3}{|l|}{ Education } \\
\hline Did not go to school & 3 & 0.5 \\
\hline Some primary school & 5 & 0.9 \\
\hline Some secondary school & 42 & 7.5 \\
\hline Finished primary school & 4 & 0.7 \\
\hline Finished secondary school & 117 & 21.0 \\
\hline Completed post-school certificate or diploma & 159 & 28.6 \\
\hline Completed bachelor degree qualification & 149 & 26.8 \\
\hline Completed post-graduation qualification & 78 & 14.0 \\
\hline
\end{tabular}


The variables used in this study consist of six groups: neighborhood environment, transport disadvantage, social exclusion, physical and mental health, SWB, and demographics. The measurements of these variables are described below. All the variables used in the analysis are from survey. The survey instrument is available in supplementary file.

\subsection{Neighborhood environment}

Measures of the neighborhood environment for each respondent's neighborhood were adapted from the Neighborhood Environment Walkability Scale (NEWS), which has been validated in several countries (Saelens, Sallis, Black, \& Chen, 2003). This scale evaluates the neighborhood environment in various dimensions, including residential density (e.g., predominance of single-family, townhouse, apartment), land-use mix - diversity (walking time to store, shop, supermarket, post office, school, fast food, restaurant, bank), land use mix - accessibility (e.g., variety of shops, other uses, and public transport stop), street connectivity, infrastructure and safety for walking (footpaths, grass/dirt strip, light, crossings and signals), neighborhood surroundings/aesthetics, traffic hazards, and crime. Each item was coded using a 4-point scale from strongly disagree to strongly agree. The final score on each dimension of the neighborhood environment was calculated based on the scoring method provided by Saelens et al. (2003). While questions were also asked about cycling, these have not been included as most were based on the use of footpaths which is illegal in Sydney.

In addition to the NEWS, we also included measures on neighborhood trust/cohesion as a measure of the neighborhood's social environment. These measures include responses to statements such as "People around my neighborhood are willing to help their neighbors"; "This is a close-knit neighborhood"; "People in this neighborhood can be trusted"; "People in this neighborhood generally don't get along (reverse scored)"; and "People in this neighborhood do not share the same values (reverse scored)". These statements are adapted from Sampson, Raudenbush, and Earls (1997). Again, each item was coded using a 4-point scale from strongly disagree to strongly agree. The measure of social environment was calculated as the mean of the scores on these five items.

\subsection{Transport disadvantage}

Transport disadvantage was measured using 13 subjective, self-reported measurements, adapted from Delbosc and Currie (2011b). Respondents were asked how easy or difficult they found covering transport costs, gaining access to reliable and safe transport, and the extent to which transport enables participation in daily activities. All statements were measured in a five-point Likert scale from "very easy" to "very difficult". Internal consistency among these statements was very high (Cronbach's alpha=0.92). The mean of the scores on these statements was used as the measure of transport disadvantage.

\subsection{Social exclusion}

Social exclusion is a complex and multifaceted concept. Its measurement may include economic, social and political dimensions (Bhalla \& Lapeyre, 1997). In this study, social exclusion was measured in three ways: social support from family, friends and neighbors; political engagement; and participation in social activities (including hobbies, sport, and patronage of community facilities and events). Respondents were asked about propensities to seek and receive help from family, friends and neighbors, as well as how often they participate in political and civic activities, ranging from attending a meeting of a formal political party to participating in a community action or church group. Some of the survey questions were adapted from Delbosc and Currie (2011b). Each question was coded using a scale of 1 (not at all) to 3 
(frequently). The three dimensions of the social exclusion measures are independent from each other, thus creating three separate measures for social exclusion. Each measure was then calculated as the sum of the scores on the questions related to that dimension.

\subsection{Physical and mental health}

Physical and mental health were measured using the 12-item short form health survey (SF-12), which has been demonstrated to be reliable and valid in the U.S. and other countries (Ware, Kosinski, \& Keller, 1996). Exploratory factor analysis was conducted using varimax rotations based on these 12 items, and two factors were extracted to represent physical and mental health respectively. The factor score for each respondent was then used as the measurement.

\subsection{Subjective well being}

Subjective well-being (SWB) was measured using the Satisfaction with Life Scale (SWLS) developed by Diener, Emmons, Larsen, and Griffin (1985). SWLS has been widely used and is a global assessment of satisfaction with one's life rather than with specific domains. It has shown strong internal reliability, and moderate temporal stability (Pavot \& Diener, 1993). SWLS consists of five items:

- In most ways, my life is close to my ideal;

- The conditions of my life are excellent;

- I am satisfied with my life;

- So far I have gotten the important things I want in life;

- If I could live my life over, I would change almost nothing.

Each item was scored using a 7-point Likert scale from strongly disagree to strongly agree. Internal consistency among these statements was very high (Cronbach's alpha $=0.87$ ). The mean of the scores on the five items was then used for the measurement of SWB.

\subsection{Demographic characteristics}

Demographic characteristics including age, gender, employment status, household income, educational background, household structure, number of vehicles owned or rented by the household, the number of bicycles owned or rented by the household, and the number of years the participant had lived in their current neighborhood. A descriptive analysis of these variables is provided in Table 2. 
Table 2: Descriptive analysis of the variables

\begin{tabular}{lcccccl}
\hline Variable & Obs. & Mean & Std. Dev. & Min & Max & Scoring method \\
\hline Neighborhood environment & & & & & & \\
Density & 560 & 304.8 & 165.1 & 173 & 865 & Weighted sum \\
Diversity & 556 & 3.2 & 0.8 & 1 & 5 & Mean \\
Access & 561 & 3.2 & 0.7 & 1 & 4 & Mean \\
Street & 559 & 3.0 & 0.7 & 1 & 4 & Mean \\
Infrastructure & 561 & 3.0 & 0.5 & 1 & 4 & Mean \\
Aesthetic & 561 & 2.9 & 0.6 & 1 & 4 & Mean \\
Traffic & 561 & 2.5 & 0.5 & 1 & 4 & Mean \\
Crime & 561 & 1.9 & 0.7 & 1 & 4 & Mean \\
Social environment & 560 & 2.8 & 0.5 & 1 & 4 & Mean \\
Transport disadvantage & & & & & & \\
Transport disadvantage & 559 & 2.1 & 0.7 & 1 & 5 & Mean \\
Social inclusion & & & & & & \\
Political engagement & 562 & 6.6 & 2.2 & 5 & 15 & Sum \\
Social help & 562 & 9.5 & 1.9 & 4 & 12 & Sum \\
Social activities & 562 & 6.4 & 1.4 & 5 & 10 & Sum \\
Health & & & & & & \\
Physical health & 556 & 0.0 & 1.0 & -2.8 & 1.1 & Factor score \\
Mental health & 556 & 0.0 & 1.0 & -2.8 & 1.4 & Factor score \\
Subjective well-being & & & & & & \\
SWLS & 562 & 4.7 & 1.3 & 1.0 & 7.0 & Mean \\
\hline & & & & & & \\
\hline
\end{tabular}

\section{Analysis methods}

Structural Equation Modelling (SEM) was used to test the conceptual model specified in Figure 2 below. This conceptual model was informed by the existing literature, and based on the original linkages underpinning the research, as illustrated in Figure 1 above. Different from multivariate regressions, SEM enables simultaneous equations to reveal the relationships among exogenous and endogenous variables. Amos 23.0 was used to estimate the SEM models.

Figure 2 expands to make explicit the hypothesis that physical and mental health, and social inclusion, have direct effects on SWB, and that transport disadvantage has both a direct and an indirect effect on SWB through its influence on physical and mental health, and social inclusion. Demographic characteristics and the neighborhood environment serve as the exogenous variables, which are hypothesized to influence all of the endogenous variables, including physical and mental health, transport disadvantage, social inclusion and SWB. All the variables in SEM were observed and measured. No latent variables were used in an effort to ensure the model structure remained as parsimonious as possible.

The SEM models were developed using maximum likelihood estimation, which assumes that observed variables follow a multivariate normal distribution. Violating this assumption can lead to underestimation of standard errors, even though it may not affect parameter estimates (Kline, 2005). We therefore estimated the models using a bootstrapping approach, which is a process of drawing repeated sample from the data (Hayes, 2009). In this study, we used Monte Carlo (or bootstrapped parameter estimates) bootstrapping set to generate 5,000 samples. Bias-corrected bootstrap confidence intervals were used to detect significant effects. 


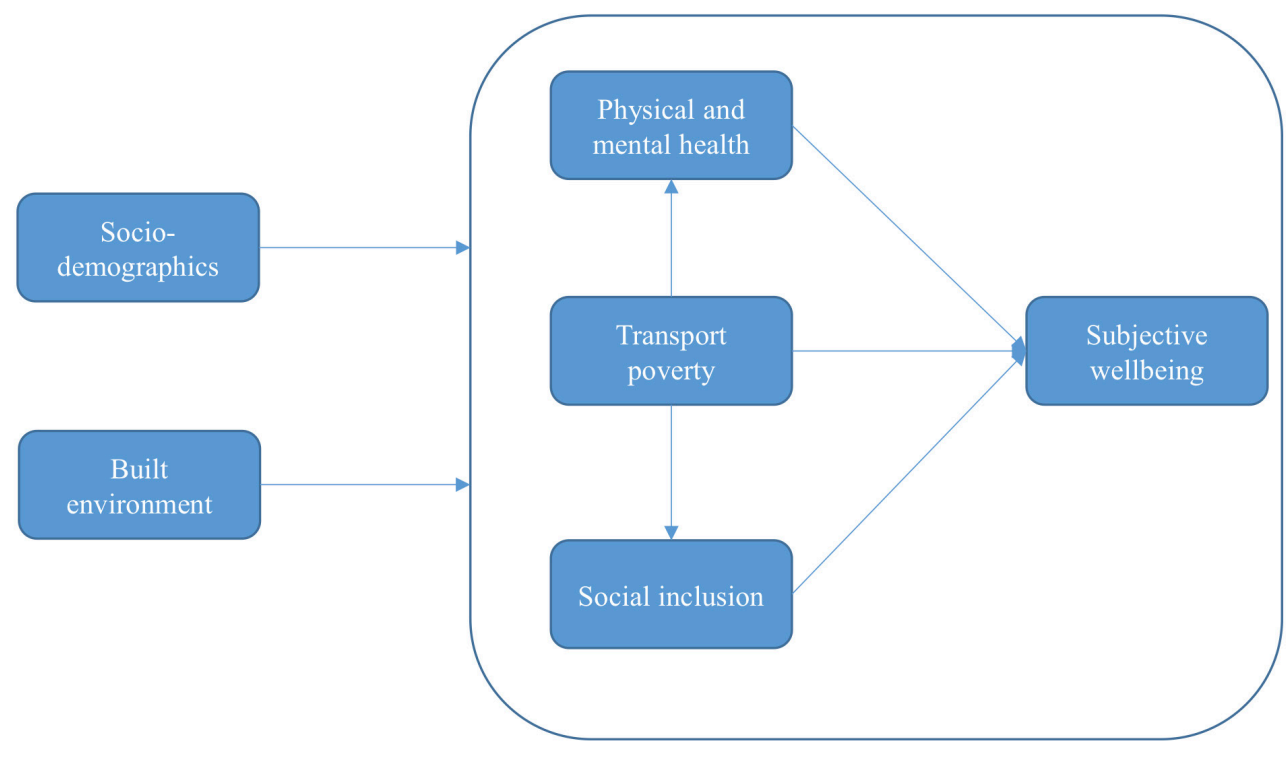

Figure 2: SEM model specification

\section{$4 \quad$ Results and discussion}

Results are presented in Tables 3 and 4. Table 3 reports the direct effects between the variables, quantifying the arrows shown in Figure 2. We previously recognized that socio-demographic and built environment variables may not only have direct effects on SWB, but also have indirect effects on SWB through influencing personal health, transport disadvantage and social exclusion. Subsequently, the total effects of these two variables on SWB were also calculated, and are reported in Table 4.

Overall, the model is a good fit to the data. The chi-square value was insignificant, $x^{2}(3)=3.978$, $\mathrm{p}=.264$ and alternative fit indices were examined to determine whether the fit was adequate. These alternative fit indices suggested a good fit according to the criteria presented in $\mathrm{Hu}$ and Bentler (1999) with $\mathrm{CFI}=1.000$, RMSEA $=.024$. Overall, the model explains about $22.2 \%, 28.5 \%, 17.9 \%, 9.4 \%, 24.9 \%$, $20.9 \%$, and $35.6 \%$ of the variations in transport disadvantage, political engagement, social help, social activities, physical health, mental health and SWB respectively.

As expected, the demographic characteristics of the respondents are associated with most of the endogenous variables. First, females, young and those in low-income households are more likely to experience transport disadvantage. This is consistent with previous studies (Dodson, Gleeson, Evans, \& Sipe, 2006; Hine \& Mitchell, 2003) that have also found these groups of people are more vulnerable to transport disadvantage. Second, those with more vehicles at home are more likely to engage in political and civic activities, and get social help from families and friends. This is also consistent with previous studies (Currie et al., 2009; Lucas, 2012; Ong \& Miller, 2005) highlighting the importance of car ownership in facilitating social inclusion. Third, those who are employed are more likely to engage in political, civic and social activities than those who are unemployed or retired. The significant association between unemployment and social isolation has also been reported in previous studies (Gallie, Paugam, \& Jacobs, 2003; Kieselbach, 2003). Fourth, older adults are more likely to have poor physical health, while those who are employed are more likely to have good physical health. Females, and those with more vehicles at 
home, are more likely to report having poor mental health, while older adults, those who are employed and those in high-income households are more likely to report having good mental health. Previous studies (Hopman et al., 2009) have also reported an association between increased age, poorer physical health and better mental health. There is also a consensus among the literature that women experience more psychological distress than men (Gove, 1984). Strong associations between income, employment and mental health are also found in previous studies (Gresenz, Sturm, \& Tang, 2001; Paul \& Moser, 2009). Finally, it is surprising that none of our socio-demographic variables are directly associated with SWB. Although the direct effects were not significant, socio-demographics may indirectly affect SWB through influencing transport disadvantage, personal health and social exclusion. As a result, the total effects of two socio-demographic variables - age and income - are significantly and positively associated with SWB, as reported in Table 4. This finding is also consistent with previous studies (Cao \& Ettema, 2014; Diener \& Suh, 1997).

The primary focus of this study is the way the neighborhood environment impacts transport disadvantage, social exclusion, health and SWB. Our results demonstrate that many of the neighborhood environment variables are significantly associated with these endogenous variables, even after controlling for demographics of the respondents.

First, neighborhoods that feature a diversity of land uses, accessibility to amenities and services, walking infrastructure, and are cohesive, are associated with less transport disadvantage. Neighborhoods with a higher perceived crime rate are associated with greater transport disadvantage.

Second, people who describe their immediate neighborhood as predominantly characterized by apartment buildings are more likely to engage in political and civic activities, receive help from families, friends and neighbors, and participate in social activities. In other words, higher density neighborhoods may help to foster social inclusion and prevent social exclusion. Those living in neighborhoods with infrastructure for walking have higher reported access to social help, than those living in non-pedestrian friendly neighborhoods. An aesthetically pleasing neighborhood (such as the presence of street trees, interesting destinations, attractive natural sights and buildings) is positively associated with political and civic engagement and participation in social activities. In addition to the physical environment, neighborhood social cohesion is positively associated with political and civic engagement and social help. It is interesting to note that perceived crime rate in the neighborhood is also positively associated with political and civic engagement. While this finding is unintuitive, other studies have found that those who perceive neighborhood disorder are more likely to engage in activities, such as speaking to a local representative or attending a community meeting, to make their communities better (Michener, 2013).

Third, neighborhood density in our model is negatively associated with both physical and mental health. Higher density neighborhoods are often planned and built on the premise that they will promote walking, cycling and other forms of physical activities that are beneficial to health. In reality, however, the results of empirical studies on the relationship between density and physical activities are mixed. Many studies have identified a positive association between density and walking for transportation (see a review by Saelens \& Handy, 2008), while others have found that the association between density and overall walking and physical activity was not significant. Forsyth, Oakes, Schmitz, and Hearst (2007) even found a negative correlation between density and leisure walking. Adding to this complexity are studies reporting both positive and negative associations between density and mental health (see a review by Clark, Stansfeld, \& Candy, 2006). Our findings only serve to confirm the ambiguity of the relationship between health and density, again exposing that it is incredibly complex. Higher residential densities may well make walking to destinations more viable by providing compact and mixed land uses. Yet too much density could prevent people from recreational walking and other outdoor activity, deterred perhaps by the ill-effects of overcrowding and crime, both variables associated with experiences 
of stress and social isolation (Kent, Thompson, \& Jalaludin, 2011). In addition to density, accessibility is positively associated with physical health, and this is probably because accessibility to services and amenities increases the walking for transportation purposes. Neighborhood social cohesion is positively associated with mental health, while perception of crime in neighborhood is negatively associated with physical health.

Fourth, the direct association between neighborhood density and SWB is weak (marginally significant, Table 3). The total effect of neighborhood density on SWB is, however, both significant ( $<<0.05$, Table 4) and positive. This suggests that people living in higher density neighborhoods report higher levels of SWB than those living in lower density ones. This is contrary to a recent study (Cao, 2016) who found a small but negative association between density and SWB. As discussed above, density can have both negative and positive impacts on health and well-being. The final impact will depend on the complex interplay between harms and advantages which may well be experienced differently by different people and at different times.

Of further relevance to well-being is that neighborhood aesthetics and social cohesion are strongly associated with SWB. Contrary to neighborhood density, these variables influence SWB mainly through direct effects. They have much greater impact on SWB than other physical environment features, in terms of either direct or total effects.

Finally, we have found significant and expected interactions between transport disadvantage, social inclusion and SWB. Transport disadvantage is negatively associated with social help, physical and mental health, and SWB, but positively associated with political and civic engagement. Those who are transport disadvantaged might have more unmet needs and are therefore more motivated to engage in political and civic activities to influence decision making. These activities are also likely to be free of charge, and therefore provide a relatively accessible way to be out and about in the community. Further, political and civic engagement is positively associated with SWB. Similarly, the ability to get help from family, friends and neighbors is also positively associated with SWB. Mental health is strongly associated with SWB, while physical health is not. Most of these findings are consistent with our hypothesis (as specified in Figure 2) and previous studies (Currie et al., 2010; Delbosc \& Currie, 2011a). 


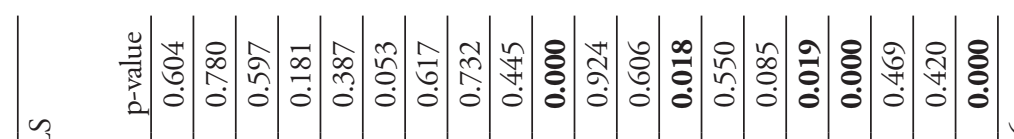

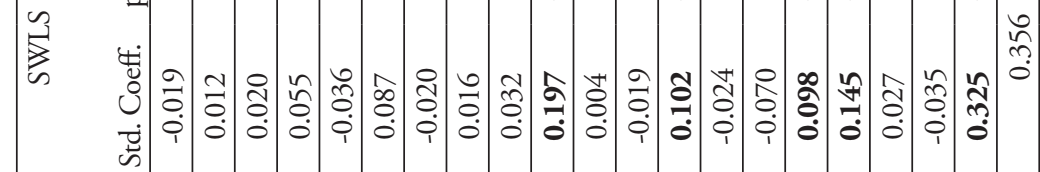

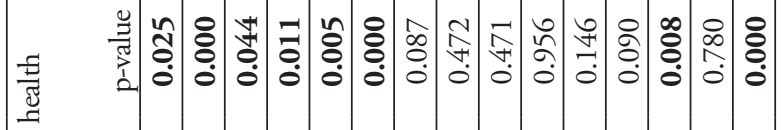

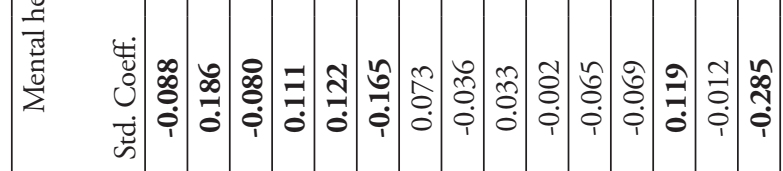

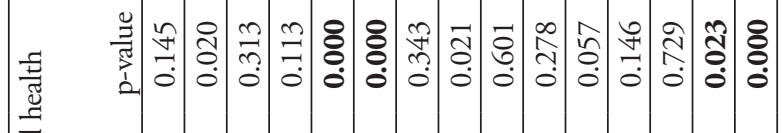

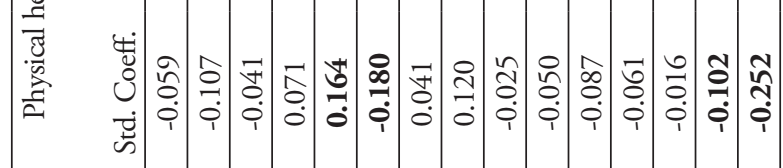

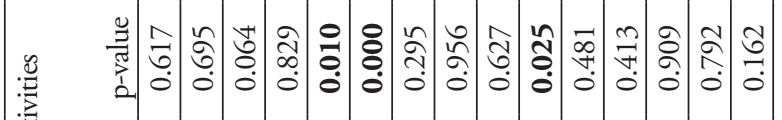

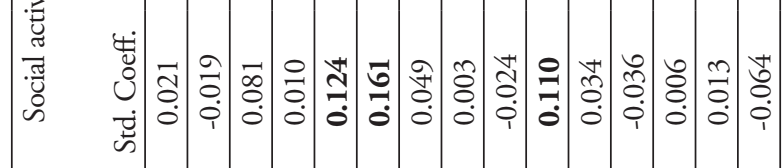

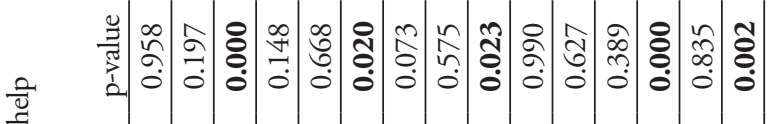

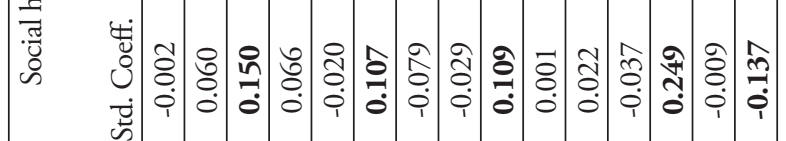

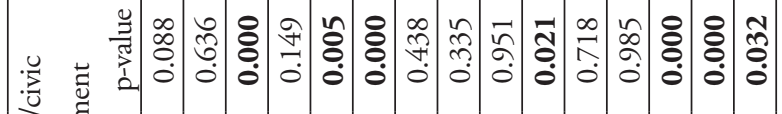

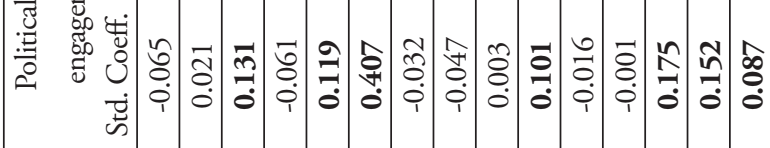

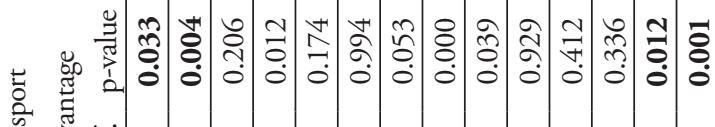

\section{害 过}

nิ 比

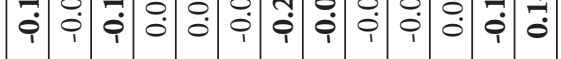


Table 4: Total effects of social demographics and neighborhood environment on SWB

\begin{tabular}{lcc}
\hline & Std. Coeff. & p-value \\
\cline { 2 - 3 } Female & -0.066 & 0.107 \\
\hline Age & $\mathbf{0 . 1 0 1}$ & $\mathbf{0 . 0 3 7}$ \\
\hline \# vehicles & 0.035 & 0.412 \\
\hline HH income & $\mathbf{0 . 1 1 1}$ & $\mathbf{0 . 0 1 3}$ \\
\hline Employed & 0.006 & 0.872 \\
\hline Density & $\mathbf{0 . 1 0 0}$ & $\mathbf{0 . 0 3 0}$ \\
\hline Diversity & -0.002 & 0.964 \\
\hline Access & 0.042 & 0.414 \\
\hline Infrastructure & 0.071 & 0.154 \\
\hline Aesthetic & $\mathbf{0 . 2 1 2}$ & $\mathbf{0 . 0 0 0}$ \\
\hline Street connectivity & 0.000 & 0.976 \\
\hline Traffic & -0.059 & 0.171 \\
\hline Social environment & $\mathbf{0 . 1 9 5}$ & $\mathbf{0 . 0 0 0}$ \\
\hline Crime & -0.042 & 0.359 \\
\hline
\end{tabular}

Note: bold font indicates $\mathrm{p}<.05$

\section{Conclusions}

This study explores the effects of the neighborhood environment on transport disadvantage, social exclusion, personal health and SWB using survey data collected in metropolitan Sydney, Australia. The data is analyzed at the individual level using structural equation modelling (SEM). The results offer some interesting insights on the connections between the neighborhood built environment and the aspects studied.

Overall, our model results support the hypothesis that a walkable neighborhood environment helps to reduce transport disadvantage and increase social inclusion. In particular, a neighborhood with higher density is associated with more engagement in political and civic activities, better access to social help, and more participation in social activities. Further, increased accessibility to amenities and services and more infrastructures for walking are both associated with less transport disadvantage. A neighborhood with an aesthetically pleasing environment is associated with more engagement in political and civic activities, and more participation in social activities generally.

More direct relationships between the neighborhood environment, health and SWB are relatively weak and complex. Neighborhood density has negative effects on both physical and mental health, but a positive effect on SWB. This confirms existing research on the complexity of links between density and health. There are obvious health benefits associated with density, for example decreased distances between origins and destinations makes active travel more viable. Yet too much density could bring crime, pollution, and crowding - all of which have negative impacts on personal health. Future research, therefore, is needed to explore the possible non-linear relationships between density and health and SWB. Putting the issue of density aside, our model also found that higher accessibility is associated with better physical health, and better aesthetics in the neighborhood are associated with higher levels of SWB.

In addition to the physical environment, the neighborhood social environment is also significantly associated with transport disadvantage, social exclusion, health and SWB. For example, a cohesive neighborhood environment is associated with less transport disadvantage, more engagement in political and civic activities, more social help, better mental health and higher SWB. In contrast, perceptions of crime 
in the neighborhood are associated with more transport disadvantage and decreased physical health.

Consistent with the previous literature (Currie et al., 2010; Lucas, 2012), transport disadvantage augments social exclusion (as measured by access to social help) and leads to lower physical and mental health, and SWB. Contrary to previous literature, transport disadvantage is positively associated with political and civic engagement. This is potentially a result of disadvantaged people seeking to fulfil unmet needs through engagement in political and community activities. This suggests that transport disadvantage has different effects on different dimensions of social exclusion, and future research should consider this in the theoretical framework. In terms of the associations between social exclusion and SWB, political engagement and social help have significant and positive effects on SWB. Finally, mental health has significant and positive effects on SWB.

This study has some limitations. It only includes perceived measures of the neighborhood environment. It is well known that objective measures and perceived measures of the neighborhood environment are not always well matched (Ma \& Dill, 2015; Van Acker, Derudder, \& Witlox, 2013), and both approaches may have independent effects on transport disadvantage, social inclusion, health and SWB which have not been tested in this study. Longitudinal studies are necessary to make rigorous causal inferences among such factors as the neighborhood environment, transport disadvantage, social inclusion, health and SWB. Of course, such data is very difficult to access for analysis.

\section{Acknowledgements}

This research was funded by a grant from the University of Sydney Business School's Early Career Research Grant scheme and conducted at the University of Sydney. Dr. Ma was a Senior Research Associate at the Institute of Transport and Logistics Studies (ITLS) at the Business School for the duration of the research. The authors thank those who participated in this research, donating their valuable time to inform better understandings of the links between cities and health. The authors also thank Patricia Mokhtarian for the discussion and constructive comments on early results of the paper. 


\section{References}

Australian Bureau of Statistics. (2011). 2011 Census QuickStats, Canberra, Australia.

Bhalla, A., \& Lapeyre, F. (1997). Social exclusion: Towards an analytical and operational framework. Development and Change, 28(3), 413-433.

Boarnet, M., \& Sarmiento, S. (1998). Can land-use policy really affect travel behavior? A study of the link between non-work travel and land-use characteristics. Urban Studies, 35(7), 1155-1170.

Cao, X., \& Ettema, D. (2014). Satisfaction with travel and residential self-selection: How do preferences moderate the impact of the Hiawatha Light Rail Transit line? Journal of Transport and Land Use, 7(3), 93-108.

Cao, X. J. (2016). How does neighborhood design affect life satisfaction? Evidence from Twin Cities. Travel Behavior and Society, 5, 68-76.

Cervero, R., Sandoval, O. S., \& Landis, J. (2002). Transportation as a stimulus of welfare-to-workprivate versus public mobility. Journal of Planning Education and Research, 22(1), 50-63. doi: 10.1177/0739456x0202200105

Church, A., Frost, M., \& Sullivan, K. (2000). Transport and social exclusion in London. Transport Policy, 7(3), 195-205.

Clark, C., Stansfeld, S., \& Candy, B. (2006). A systematic review on the effect of the physical environment on mental health. Epidemiology, 17(6), S527.

Currie, G., Richardson, T., Smyth, P., Vella-Brodrick, D., Hine, J., Lucas, K., Stanley, J., Morris, J. Kinnear, R., \& Stanley, J. (2009). Investigating links between transport disadvantage, social exclusion and well-being in Melbourne-preliminary results. Transport Policy, 16(3), 97-105.

Currie, G., Richardson, T., Smyth, P., Vella-Brodrick, D., Hine, J., Lucas, K., Stanley, J., Morris, J. Kinnear, R., \& Stanley, J. (2010). Investigating links between transport disadvantage, social exclusion and well-being in Melbourne-updated results. Research in Transportation Economics, 29(1), 287-295.

Currie, G., \& Stanley, J. (2007). No way to go: Transport and social disadvantage in Australian communities. Melbourne, Australia: Monash University ePress.

Daniels, R., \& Mulley, C. (2012). Planning public transport networks-the neglected influence of topography. Journal of Public Transportation, 15(4), 23-41.

Delbosc, A., \& Currie, G. (2011a). Exploring the relative influences of transport disadvantage and social exclusion on well-being. Transport Policy, 18(4), 555-562.

Delbosc, A., \& Currie, G. (2011b). Transport problems that matter-social and psychological links to transport disadvantage. Journal of Transport Geography, 19(1), 170-178.

Delbosc, A., \& Currie, G. (2011c). The spatial context of transport disadvantage, social exclusion and well-being. Journal of Transport Geography, 19(6), 1130-1137. doi: 10.1016/j.jtrangeo.2011.04.005

Diener, E. (2000). Subjective well-being: The science of happiness and a proposal for a national index. American Psychologist, 55(1), 34-43.

Diener, E., Emmons, R. A., Larsen, R. J., \& Griffin, S. (1985). The satisfaction with life scale. Journal of Personality Assessment, $49(1), 71-75$.

Diener, E., \& Suh, E. (1997). Measuring quality of life: Economic, social, and subjective indicators. Social Indicators Research, 40(1-2), 189-216.

Dodson, J., Gleeson, B., Evans, R., \& Sipe, N. (2006). Transport disadvantage in the Australian metropolis: Towards new concepts and methods. Urban Policy and Research, 24(4), 433-453.

Downes-Le Guin, T., Baker, R., Mechling, J., \& Ruylea, E. (2012). Myths and realities of respondent engagement in online surveys. International Journal of Market Research, 54(5), 1-21. 
Ettema, D., Gärling, T., Olsson, L. E., \& Friman, M. (2010). Out-of-home activities, daily travel, and subjective well-being. Transportation Research Part A: Policy and Practice, 44(9), 723-732.

Ewing, R., \& Cervero, R. (2010). Travel and the built environment. Journal of the American Planning Association, 76(3), 265-294. doi: 10.1080/01944361003766766

Forsyth, A., Oakes, J. M., Schmitz, K. H., \& Hearst, M. (2007). Does residential density increase walking and other physical activity? Urban Studies, 44(4), 679-697.

Frank, L. D., \& Engelke, P. O. (2001). The built environment and human activity patterns: Exploring the impacts of urban form on public health. Journal of Planning Literature, 16(2), 202-218.

Gallie, D., Paugam, S., \& Jacobs, S. (2003). Unemployment, poverty and social isolation: Is there a vicious circle of social exclusion? European Societies, 5(1), 1-32.

Gove, W. R. (1984). Gender differences in mental and physical illness: The effects of fixed roles and nurturant roles. Social Science and Medicine, 19(2), 77-84.

Grengs, J. (2010). Job accessibility and the modal mismatch in Detroit. Journal of Transport Geography, 18(1), 42-54. doi: 10.1016/j.jtrangeo.2009.01.012

Gresenz, C. R., Sturm, R., \& Tang, L. (2001). Income and mental health: Unraveling community and individual level relationships. Journal of Mental Health Policy and Economics, 4(4), 197-204.

Hayes, A. F. (2009). Beyond Baron and Kenny: Statistical mediation analysis in the new millennium. Communication Monographs, 76(4), 408-420.

Hine, J., \& Mitchell, F. (2003). Transport disadvantage and social exclusion: Exclusionary mechanisms in transport in urban Scotland. Farnham, UK: Ashgate Publishing, Ltd.

Hopman, W., Harrison, M., Coo, H., Friedberg, E., Buchanan, M., \& VanDenKerkhof, E. (2009). Associations between chronic disease, age and physical and mental health status. Chronic Diseases in Canada, 29(3), 108-116.

Hu, L.-T., \& Bentler, P. M. (1999). Cutoff criteria for fit indexes in covariance structure analysis: Conventional criteria versus new alternatives. Structural Equation Modeling, 6(1), 1-55.

Hurni, A. (2007). Marginalized groups in western Sydney: The experience of sole parents and unemployed young people. In G. Currie \& J. Stanley (Eds.), No way to go: Transport and social disadvantage in Australian communities. Clayton Victoria, Australia: Monash University ePress.

Kent, J., Thompson, S., \& Jalaludin, B. (2011). Healthy built environments: A review of the literature. Kensington, New South Wales: Healthy Built Environments Program, City Futures Research Centre, The University of New South Wales.

Kent, J. L., \& Thompson, S. (2014). The three domains of urban planning for health and well-being. Journal of Planning Literature, 29(3), 239-256.

Kieselbach, T. (2003). Long-term unemployment among young people: The risk of social exclusion. American Journal of Community Psychology, 32(1-2), 69-76.

Kline, R. B. (2005). Principles and practice of structural equation modeling. New York: Guilford Press.

Lucas, K. (2012). Transport and social exclusion: Where are we now? Transport policy, 20, 105-113.

Ma, L., \& Dill, J. (2015). Associations between the objective and perceived built environment and bicycling for transportation. Journal of Transport and Health, 2(2), 248-255.

Michener, J. (2013). Neighborhood disorder and local participation: Examining the political relevance of "Broken Windows." Political Behavior, 35(4), 777-806.

Ong, P. M., \& Miller, D. (2005). Spatial and transportation mismatch in Los Angeles. Journal of Planning Education and Research, 25(1), 43-56. doi: 10.1177/0739456x04270244

Paul, K. I., \& Moser, K. (2009). Unemployment impairs mental health: Meta-analyses. Journal of Vocational Behavior, 74(3), 264-282.

Pavot, W., \& Diener, E. (1993). Review of the Satisfaction With Life Scale. Psychological Assessment, 
5(2), 164-172.

Pfeiffer, D., \& Cloutier, S. (2016). Planning for happy neighborhoods. Journal of the American Planning Association, 82(3), 267-279.

Saelens, B. E., \& Handy, S. L. (2008). Built environment correlates of walking: A review. Medicine and Science in Sports and Exercise, 40(7), S550-S566.

Saelens, B. E., Sallis, J. F., Black, J. B., \& Chen, D. (2003). Neighborhood-based differences in physical activity: An environment scale evaluation. American Journal of Public Health, 93(9), 1552-1558.

Sampson, R. J., Raudenbush, S. W., \& Earls, F. (1997). Neighborhoods and violent crime: A multilevel study of collective efficacy. Science, 277(5328), 918-924.

Stanley, J. K., Hensher, D. A., Stanley, J. R., \& Vella-Brodrick, D. (2011). Mobility, social exclusion and well-being: Exploring the links. Transportation Research Part A: Policy and Practice, 45(8), 789-801.

Thompson, S., \& Kent, J. (2014). Healthy built environments supporting everyday occupations: Current thinking in urban planning. Journal of Occupational Science, 21(1), 25-41.

Transport for London. (2010). Measuring public transport accessibility levels: PTALs summary. London: Transport for London.

Van Acker, V., Derudder, B., \& Witlox, F. (2013). Why people use their cars while the built environment imposes cycling. Journal of Transport and Land Use, 6(1), 53-62.

Ware, J. E., Kosinski, M., \& Keller, S. D. (1996). A 12-item short-form health survey: Construction of scales and preliminary tests of reliability and validity. Medical Care, 34(3), 220-233. 